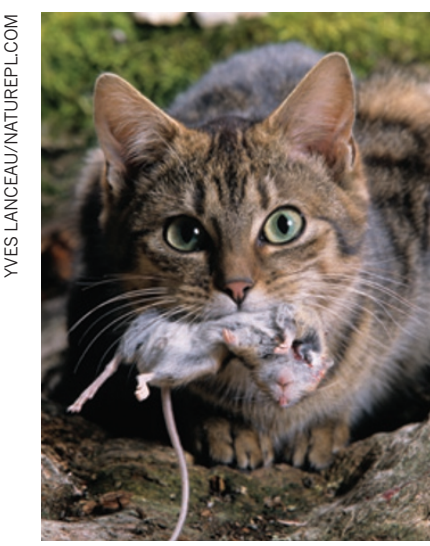

ECOLOGY

\section{Cats are enemy} number one

Free-ranging domestic cats in the United States kill many more birds and mammals than previously thought, making them possibly the top anthropogenic killer of US wildlife.

Scott Loss at the Smithsonian Conservation Biology Institute, Washington DC, and his colleagues conducted a systematic review of studies on cat population sizes and predation behaviour. They analysed the data to estimate mortality caused by US domestic cats - including those living on farms, pet cats that spend at least some of their time outdoors, stray cats fed by humans and feral felines. The researchers estimate that these cats kill 1.4 billion to 3.7 billion birds and 6.9 billion to 20.7 billion mammals annually, possibly exceeding other humanrelated causes of death such as habitat destruction or collisions with vehicles or buildings.

These numbers suggest that cats could be endangering some species in certain regions, the authors say. Nature Commun. 4, 1396 (2013)

\section{PHYSICS}

\section{A tabletop neutron source}

Researchers interested in using neutrons to probe materials currently need access to particle accelerators or fission reactors, but a tabletop neutron-imaging device may be on the way. Markus Roth at the Technical University of Darmstadt, Germany, and his colleagues used a 200-terawatt laser at the Los Alamos National Laboratory in New Mexico to generate a high-energy neutron beam that can be directed at neutronabsorbing objects.

The team produced the beam by sending laser pulses into a deuterium-rich plastic target, knocking deuterons (which consist of a proton and a neutron) into a beryllium rod that then shot neutrons forwards. The researchers' technique used less than onequarter of the laser energy and generated an order of magnitude more neutrons in a forward directed beam than previous methods.

The group hopes that its approach could be used to create a portable neutron source for use in university laboratories.

Phys. Rev. Lett. 110, 044802 (2013) \section{EVOLUTION \\ Bird behaviour spurs evolution}

Shifts in environmental conditions are thought to drive evolutionary change, but biologists have debated whether the way that animals interact with their environment also plays a part. A study of pigeons and doves suggests that changes in behaviour can drive alterations in the birds' shapes.

Oriol Lapiedra of the Centre for Ecological Research and Forestry Applications in Barcelona, Spain, and his colleagues used evolutionary models to pinpoint links between changes

COMMUNITY CHOICE

The most viewed papers in science

\title{
Protein production on the clock
}

\section{( ) HIGHLY READ \\ on www. \\ plosbiology.org in \\ January}

into protein.

Frédéric Gachon at the University of Lausanne in Switzerland and his colleagues found that mRNAs that encode components of the translation machinery including some involved in making ribosomes - are rhythmically expressed in the livers of mice. Production of these RNAs peaks in the nocturnal animals shortly before nightfall, when the energy needed for protein synthesis is most likely to be available.

PLoS Biol. 11, e1001455 (2013)

in behaviour and physical characteristics in 156 species of dove and pigeon (one, Caloenas nicobarica, pictured). The authors found that when some birds changed from terrestrial to tree-based foraging behaviour, this accelerated the evolution of shorter hindlimb bones and longer tails - traits that are useful in an arboreal lifestyle.

However, the demands of foraging in trees seems to limit further diversification, potentially representing an "evolutionary dead-end", the authors say.

Proc. R. Soc. B http://dx.doi. org/10.1098/rspb.2012.2893 (2013)

\section{REPRODUCTIVE BIOLOGY}

\section{Puberty controlled} by DNA changes

Sexual maturation in female mammals is controlled by specific changes to the chemical groups attached to DNA - a type of 'epigenetic' change - which results in the coordinated action of multiple genes.

Puberty begins with a rise in the secretion of gonadotropin-releasing hormone $(\mathrm{GnRH})$ by a region of the brain called the hypothalamus, but the mechanism that coordinates the genes involved has been unclear. Alejandro Lomniczi and Sergio Ojeda at Oregon Health \& Science University in Portland and their colleagues report that decreasing levels of a genesilencing molecule called EED may control the process in rats. EED regulates the expression of a gene called Kiss 1, which encodes a protein that helps to stimulate $\mathrm{GnRH}$ production. The addition of methyl groups to the regulatory region of the EED gene lowers EED expression just before the onset of puberty, resulting in a rise in Kiss 1 activity and more frequent pulses of GnRH from the hypothalamus.

Nature Neurosci. http://dx. doi.org/10.1038/nn.3319 (2013)

\section{NATURE.COM}

For the latest research published by Naturevisit:

www.nature.com/latestresearch 